\section{Standardised incidence ratios (SIRs) for cancer after renal transplant in systemic lupus erythematosus (SLE) and non-SLE recipients}

Rosalind Ramsey-Goldman, ${ }^{1}$ Amarpali Brar, ${ }^{2}$ Carrie Richardson, ${ }^{1}$ Moro O Salifu, ${ }^{2}$ Ann Clarke, ${ }^{3}$ Sasha Bernatsky, ${ }^{4}$ Dimitre G Stefanov, ${ }^{5}$ Rahul M Jindal ${ }^{6}$
To cite: Ramsey-Goldman $\mathrm{R}$, Brar A, Richardson C, et al. Standardised incidence ratios (SIRs) for cancer after renal transplant in systemic lupus erythematosus (SLE) and non-SLE recipients. Lupus Science \& Medicine 2016;3: e000156. doi:10.1136/lupus2016-000156

Prior presentations: Portions of this work have previously been presented at the October 2013 American College of Rheumatology Annual Meeting, San Diego, California, USA.

Received 15 March 2016 Revised 19 April 2016 Accepted 23 April 2016

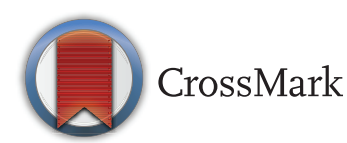

For numbered affiliations see end of article.

\section{Correspondence to} Dr Rosalind RamseyGoldman;

rgramsey@northwestern.edu

\section{ABSTRACT}

Objective: We investigated malignancy risk after renal transplantation in patients with and without systemic lupus erythematosus (SLE).

Methods: Using the United States Renal Data System from 2001 to 2009, 143652 renal transplant recipients with and without SLE contributed 585420 patientyears of follow-up to determine incident cancers using Medicare claims codes. We calculated standardised incidence ratios (SIRs) of cancer by group using age, sex, race/ethnicity-specific and calendar year-specific cancer rates compared with the US population.

Results: 10160 cancers occurred at least 3 months after renal transplant. Overall cancer risk was increased in both SLE and non-SLE groups compared with the US general population, SIR $3.5(95 \% \mathrm{CI} 2.1$ to 5.7$)$ and SIR 3.7 (95\% Cl 2.4 to 5.7), respectively. Lip/ oropharyngeal, Kaposi, neuroendocrine, thyroid, renal, cervical, lymphoma, liver, colorectal and breast cancers were increased in both groups, whereas only melanoma was increased in SLE and lung cancer was increased in non-SLE. In Cox regression analysis, SLE status (HR 1.1, 95\% Cl 0.9 to 1.3) was not associated with increased risk of developing cancer, adjusted for other independent risk factors for developing cancer in renal transplant recipients. We found that smoking (HR $2.2,95 \% \mathrm{Cl} 1.2$ to 4.0 ), cytomegalovirus positivity at time of transplant (HR 1.3, 95\% Cl 1.2 to 1.4), white race (HR 1.2, $95 \% \mathrm{Cl} 1.2$ to 1.3) and older recipient age at time of transplantation (HR $1.095 \% \mathrm{Cl} 1.0$ to 1.2) were associated with an increased risk for development of cancer, whereas shorter time on dialysis, Epstein-Barr virus or HIV were associated with a lower risk for development of cancer.

Conclusions: Cancer risk in renal transplant recipients appeared similar in SLE and non-SLE subjects, aside from melanoma. Renal transplant recipients may need targeted counselling regarding surveillance and modifiable risk factors.

\section{INTRODUCTION}

Lupus nephritis is among the most common and serious manifestations of systemic lupus erythematosus (SLE), affecting approximately $40 \%$ of blacks and $18.8 \%$ of whites with SLE, $10 \%-20 \%$ of whom will progress to end-stage renal disease (ESRD). ${ }^{1}$ Despite an up to $50 \%$ risk of recurrence of lupus nephritis in the transplanted kidney, ${ }^{1}{ }^{2}$ graft survival, graft function and overall mortality are similar to those who undergo transplantation for other conditions. ${ }^{3} 4$

It has been shown that renal transplantation improves survival in SLE patients with ESRD. ${ }^{5}$ There is an increased risk of haematological malignancy, lung cancer, melanoma, thyroid cancer, vulvovaginal cancer and cancer of the lip associated with renal transplantation. $^{6-9}$ For patients with SLE, who have an elevated risk of certain cancers at baseline, the risk of malignancy after renal transplantation may be even greater. ${ }^{10-14}$

To date, the risk of malignancy after renal transplantation in patients with and without SLE compared with the general population has not been quantified. We examined the risk of malignancy in renal transplant recipients with SLE and non-SLE recipients compared with the general population.

\section{METHODS}

\section{Data source}

The United States Renal Data System (USRDS) is a national registry of people receiving renal replacement therapy due to ESRD. ${ }^{15}$ The USRDS is a unique and powerful tool as all renal transplants in the USA are included as mandated by law. The USRDS includes data on approximately $92 \%$ of patients receiving dialysis in the USA and $100 \%$ of the recipients of renal transplantation. As of 2013, the USRDS had tracked $>2.4$ million individuals, 413493 of whom had undergone renal transplantation (USRDS 2013 report). Mandatory annual 
follow-up data are collected on all transplant recipients, including reporting of post-transplant malignancies, until graft failure or patient death. Available demographics include birth date, sex, race/ethnicity, date of renal transplantation (ie, date first entered into the registry at each site) and the indication for ESRD (with a specific category for SLE). Data from the USRDS have been validated with $90 \%$ agreement with source documents; ${ }^{16}$ however, smoking is known to be grossly underreported. ${ }^{17}$ Deidentified clinical data were used from the USRDS, and this human subjects research falls under the exemption of Department of Health and Human Services (DHHS) regulation (46.101(b), \#4).

\section{Identification of cohort}

A cohort of 143652 renal transplant recipients contributing 585420 patient-years of follow-up were identified between 2001 and 2009 from the USRDS. Patients were stratified by primary cause of ESRD into SLE $(n=4289$ (3\%), contributing 18435 patient-years) and non-SLE (n=139 363 (97\%), contributing 566985 patient-years).

\section{Ascertainment of cancer outcomes}

International Classification of Diseases (ICD)-9 codes for cancers were identified on the basis of a single Medicare claim code for cancer within billing and hospitalisation data from 2000 to 2009. Established algorithms were used to eliminate duplicate Medicare claims for the same patient. We excluded claims made in the first three months post-transplantation as these could include pre-existing undiagnosed malignancy. Cancers were identified from Medicare physician claims data using the following ICD-9 codes and their subcodes: 140-149, 150159, 160-165, 170-176, 179-189, 190-199, 200-209 and 230-234. Cancer incidence was expressed per 100000 patient-years. The expected number of cancers was derived from Surveillance Epidemiology and End Results program (SEER) general population cancer data from 2000 to 2009, accounting for age and sex.

\section{Statistical analyses}

Continuous variables are presented as means \pm SD. Standardised incidence ratios (SIRs) were calculated as the ratio of observed to expected cancer incidence. The observed incidence during the study interval was calculated using the total number of cancers observed. The expected incidence was calculated by multiplying each person-year at risk in the cohort by the general population age, sex and calendar year-specific SEER cancer rates. The person-years at risk for each subject were calculated by subtracting the entry dates (renal transplant) from the earliest of three exit dates (cancer, death or end of the cohort study interval). SIRs were generated for overall and for site-specific cancers according to SLE status (SLE or non-SLE), ethnicity (Hispanic or non-Hispanic) and race (white or non-white). The 95\% CIs were calculated for the SIRs using Poisson parameters. We also performed Cox regression analysis to compare time from renal transplant to cancer diagnoses between SLE and non-SLE groups, adjusted for other independent risk factors for developing cancer in renal transplant recipients. $\mathrm{p}<0.05$ was considered statistically significant.

\section{Study power}

The power calculations were based on a cohort of 150000 renal transplant subjects, with a median duration of follow-up of 5 (maximum 11) years and an annual overall malignancy incidence of 0.005 per year in the general population. This study was powered to detect a 1.15-fold increase in overall cancer risk in all renal transplant patients (compared with the general population) with $>95 \%$ power, with a two-sided type 1 error of $5 \%$. We based our power calculations on an estimate that 1650 patients in the USRDS would have undergone renal transplantation for SLE-related renal disease. This was based on estimations that 1 in 2000 Americans may have SLE, and $10 \%$ of patients with SLE may require renal transplantation as a result of SLE-related renal disease. Thus, a twofold increased cancer risk (compared with the remainder of the renal transplant population) for this subgroup would be detected with a power of $>95 \%$, and a 1.75 -fold increased cancer risk with a power of $>85 \%$, with a two-sided type 1 error of $5 \%$.

\section{RESULTS}

In total, 143652 subjects, including 4289 with SLE, were observed for a total of 585420 patient-years, an average

Table 1 Baseline characteristics in systemic lupus erythematosus (SLE) and non-SLE renal transplant recipients in the USA (2001-2009)

\begin{tabular}{|c|c|c|c|}
\hline Characteristic & $\begin{array}{l}\text { SLE } \\
(\mathrm{N}=4289)\end{array}$ & $\begin{array}{l}\text { Non-SLE } \\
(\mathrm{N}=139361)\end{array}$ & $\begin{array}{l}p \\
\text { Value }\end{array}$ \\
\hline Age at transplant & $42.0 \pm 14.2$ & $47.3 \pm 15.5$ & 0.0001 \\
\hline \multicolumn{4}{|l|}{ Race } \\
\hline White & $39 \%$ & $60 \%$ & \multirow[t]{4}{*}{0.0001} \\
\hline Black & $41 \%$ & $24 \%$ & \\
\hline Asian & $5 \%$ & $4 \%$ & \\
\hline Native & $1 \%$ & $1 \%$ & \\
\hline \multicolumn{4}{|l|}{ American } \\
\hline Other & $14 \%$ & $11 \%$ & \\
\hline \multicolumn{4}{|l|}{ Ethnicity } \\
\hline Hispanic & $18 \%$ & $12 \%$ & 0.0001 \\
\hline \multicolumn{4}{|l|}{ Sex } \\
\hline Male & $39 \%$ & $61 \%$ & 0.0001 \\
\hline Current smoker & $0.2 \%$ & $0.3 \%$ & NS \\
\hline BMI & $24.4 \pm 5.5$ & $26.3 \pm 5.9$ & 0.0001 \\
\hline HCV positivity & $4 \%$ & $6 \%$ & 0.0001 \\
\hline HIV positivity & $0.1 \%$ & $0.4 \%$ & 0.022 \\
\hline EBV positivity & $86 \%$ & $84 \%$ & 0.005 \\
\hline CMV positivity & $55.3 \%$ & $52.5 \%$ & 0.0001 \\
\hline $\begin{array}{l}\text { Dialysis vintage } \\
\text { (years) }\end{array}$ & $8.5 \pm 6.0$ & $7.7 \pm 6.0$ & 0.001 \\
\hline
\end{tabular}




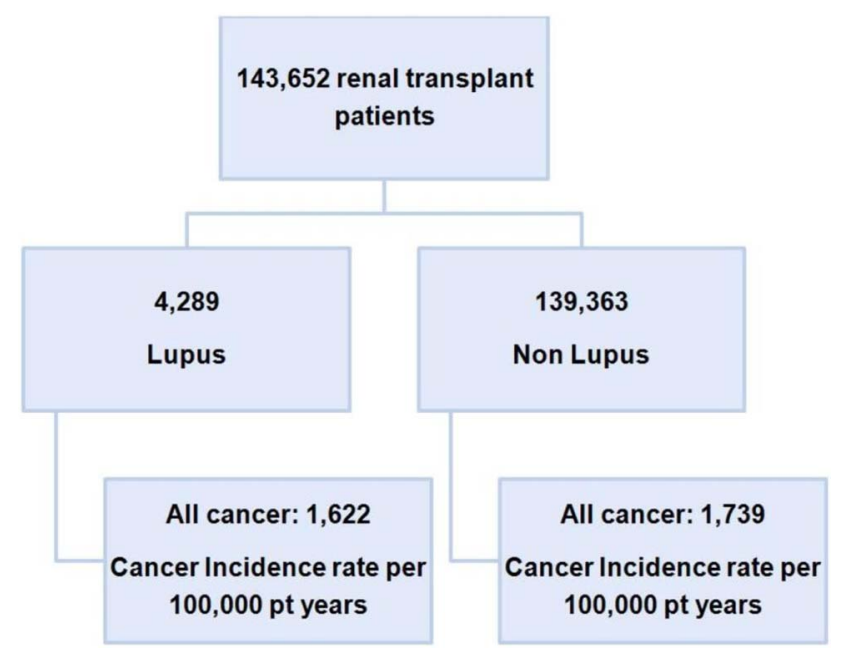

Figure 1 Flow diagram of the study design. Further subdivided by cancer type and standard incidence ratios were calculated as the ratio of observed to expected cancer incidence rates in each cancer type.

of 4 years per patient. Also, 10160 cancers (299/4289, $7 \%$ in SLE and 9861/139 363, 7.1\% in non-SLE transplant recipients) occurred at least three months after renal transplantation. There were significant differences in characteristics between the SLE and non-SLE renal transplant cohort recipients as shown in table 1 . The SLE cohort was significantly younger at age of transplantation with a lower body mass index (BMI), less likely to be white, more likely to be Hispanic, less likely to be male, less likely to test positive at time of transplant for hepatitis $\mathrm{C}$ virus (HCV) or HIV, more likely to test positive at time of transplant for Epstein-Barr virus (EBV) and cytomegalovirus (CMV), and had been on dialysis longer than the non-SLE cohort. Figure 1 gives the flow diagram of the study design.

As shown in figure 2 and table 2, compared with the US general population, overall cancer risk was increased in both SLE and non-SLE groups, SIR 3.5; 95\% CI 2.1 to
5.7 and SIR 3.7; 95\% CI 2.4 to 5.7, respectively. Lip/oropharyngeal, Kaposi, neuroendocrine, thyroid, renal, cervical, lymphoma, liver, colorectal and breast cancers were increased in both the SLE and non-SLE compared with the general US population. Non-SLE subjects had increased risk for lung cancer compared with the US general population.

As shown in tables 3 and 4, when stratifying by race or ethnicity in the SLE groups, most of the subgroups had evidence of increased risk, and because of wide CIs, we were unable to detect any differences in cancer risk among the race/ethnic SLE groups. However, in the non-SLE group, there was evidence of an increased risk of thyroid, renal and melanoma cancers in the nonwhite group versus whites, and increased ovarian cancer risk in Hispanics versus non-Hispanics.

In Cox regression analysis, SLE status (HR 1.1, 95\% CI 0.9 to 1.3 ) was not associated with increased risk of developing cancer, adjusted for other risk factors identified in the descriptive analyses (table 5 ). We found that smoking (HR 2.2, 95\% CI 1.2 to 4.0 ), CMV positivity at time of transplant (HR 1.3, 95\% CI 1.2 to 1.4 ), white race (HR 1.2, 95\% CI 1.2 to 1.3 ) and older recipient age at time of transplantation (HR 1.0, 95\% CI 1.0 to 1.2) were associated with an increased risk for development of cancer, whereas shorter time on dialysis, EBV or HIV were associated with a lower risk for development of cancer.

Additional analysis by sex showed no significant difference in the proportions of men by overall cancer status in the SLE group (with cancer $38.1 \%$ vs without cancer $39.2 \% ; \mathrm{p}=0.759$ ) or the non-SLE group (with cancer $61.0 \%$ vs without cancer $61.0 \%$; $\mathrm{p}=0.995$ ). We examined risk of liver cancer or lymphoma based on HCV or EBV status as time of transplant and were unable to detect a clear association between these viral infections and risk of these malignancies in the SLE or the non-SLE groups. HIV status was not further explored due to the small sample size of those infected with this virus. Although
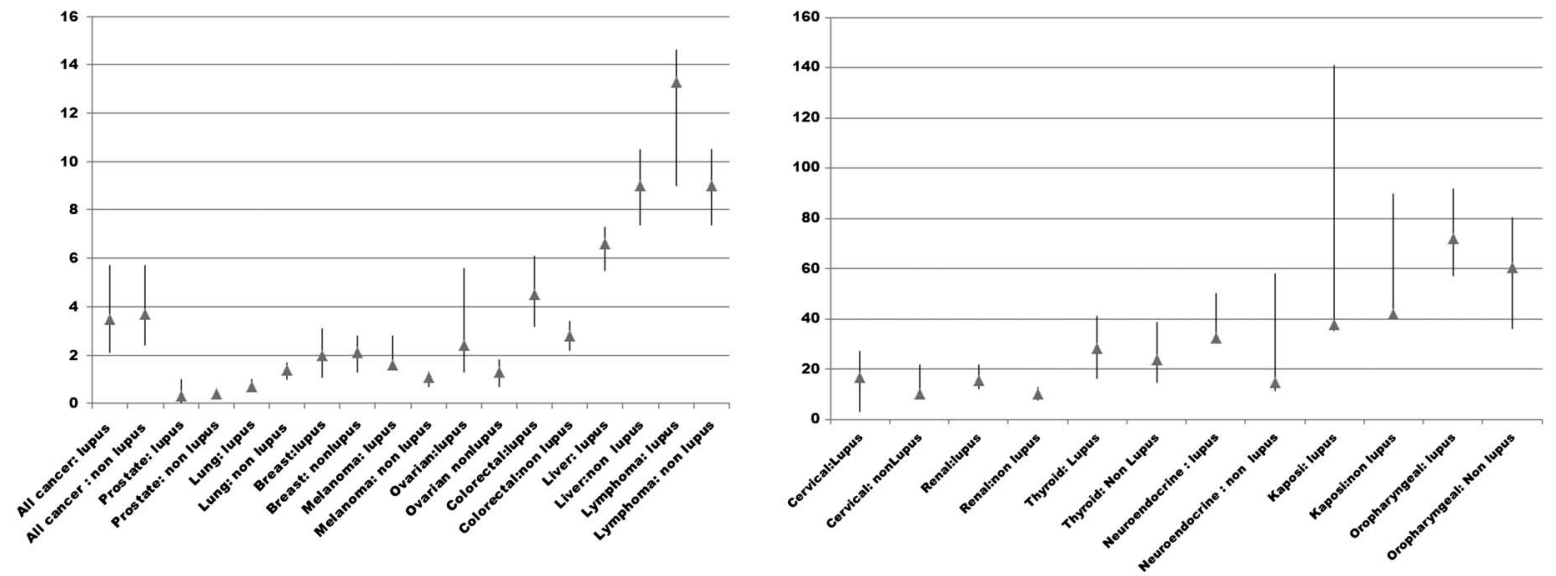

Figure 2 Standardised incidence ratios in US renal transplant recipients, categorised by lupus versus non-lupus. X-axis: type of cancer; Y-axis: standardised incidence ratio. 
Table 2 Standardised incidence ratios (SIRs) and 95\% Cls in US renal transplant recipients compared with the US general population

\begin{tabular}{|c|c|c|c|c|c|c|}
\hline \multirow[b]{2}{*}{ Cancer type } & \multicolumn{3}{|l|}{ SLE } & \multicolumn{3}{|l|}{ Non-SLE } \\
\hline & $\begin{array}{l}\text { Observed } \\
\text { cases }^{\star}\end{array}$ & $\begin{array}{l}\text { Expected } \\
\text { cases* }^{*}\end{array}$ & SIR (95\% CI) & $\begin{array}{l}\text { Observed } \\
\text { cases }^{\star}\end{array}$ & $\begin{array}{l}\text { Expected } \\
\text { cases* }^{*}\end{array}$ & SIR (95\% CI) \\
\hline All cancers & 1622 & 466 & 3.5 (2.1 to 5.7$)$ & 1739 & 469 & 3.7 (2.4 to 5.7$)$ \\
\hline $\begin{array}{l}\text { Lip/ } \\
\text { oropharyngeal }\end{array}$ & 791 & 11 & 72 (57.3 to 92.0$)$ & 665 & 11 & $60.4(36.2$ to 80.1$)$ \\
\hline Kaposi & 38 & 1 & 38 (35.2 to 141.1$)$ & 42 & 1 & 42 (55.2 to 89.9$)$ \\
\hline Neuroendocrine & 163 & 5 & 32.6 (30.7 to 50.2$)$ & 74 & 5 & 14.8 (11.3 to 58.2$)$ \\
\hline Thyroid & 283 & 10 & 28.3 (16.2 to 41.2$)$ & 238 & 10 & 23.8 .5 (14.6 to 38.5$)$ \\
\hline Renal & 217 & 14 & 15.5 (12.3 to 21.7$)$ & 142 & 14 & 10.1 (7.6 to 12.6$)$ \\
\hline Cervical & 133 & 8 & 16.6 (3.0 to 27.3$)$ & 144 & 9 & 16.7 (11.7 to 21.6$)$ \\
\hline Lymphoma & 293 & 22 & 13.3 (9.0 to 14.6$)$ & 194 & 22 & 9.0 (7.4 to 10.5$)$ \\
\hline Liver & 40 & 6 & 6.6 (5.5 to 7.3$)$ & 17 & 7 & 9.0 (7.4 to 10.5$)$ \\
\hline Colorectal & 222 & 49 & 4.5 (3.2 to 6.1$)$ & 150 & 50 & $2.8(2.2$ to 3.4$)$ \\
\hline Ovarian & 32 & 13 & 2.4 (1.3 to 5.6$)$ & 17 & 13 & $1.3(0.7$ to 1.8$)$ \\
\hline Melanoma & 27 & 20 & 1.4 (1.6 to 2.8$)$ & 22 & 20 & $1.1(0.7$ to 1.3$)$ \\
\hline Breast & 255 & 127 & $2.0(1.1$ to 3.1$)$ & 280 & 127 & 2.1 (1.3 to 2.8$)$ \\
\hline Lung & 43 & 65 & $0.7(0.6$ to 1.0$)$ & 90 & 64 & $1.4(1.0$ to 1.7$)$ \\
\hline Prostate & 54 & 163 & $0.33(0.01$ to 1.0$)$ & 65 & 163 & $0.4(0.2$ to 0.5$)$ \\
\hline
\end{tabular}

${ }^{*}$ Observed and expected cases reported per 100000 person-years.

SLE, systemic lupus erythematosus.

there was a significant statistical difference between the BMI in the SLE versus non-SLE, the difference was not clinically significant and not further examined by subgroups of BMI. There was no difference in average time to cancer occurrence following transplant in the SLE group $(2.2 \pm 1.7)$ versus non-SLE group $(2.1 \pm 1.7)$ years.

\section{DISCUSSION}

Our study is the first to use a large national database to examine cancer risk after renal transplantation in patients with and without SLE. The data suggest that, with an average of 4 years of follow-up, patients with SLE have an increased overall risk of cancer that is similar to the risk in the non-SLE renal transplantation population. We did find a suggestion of an increased risk of melanoma in SLE versus non-SLE renal transplant recipients. Smoking, increased recipient age at time of transplantation, CMV positivity at time of transplantation and white race were associated with higher risk for development of cancer, whereas SLE status did not modify the risk of cancer.

A strength of our study was the large number of patients with SLE. Although the total sample size of 143652 renal transplant recipients fell short of the original estimate of 150000 , the overall sample size was large, with $>500000$ patient-years of follow-up. Still, this resulted in only an average of 4 years of follow-up per patient (with some patients only contributing 1 or 2 years of follow-up), which does not adequately describe long-term events.

Although there were differences in baseline variables, the absolute differences were often small. For example, although HIV and HCV positivity occurred less frequently and EBV positivity more frequently in the SLE group compared with the non-SLE group, the absolute differences were small. Furthermore, the risks of EBV-related malignancy, namely lymphoma, ${ }^{18}$ HIV-related malignancies such as Kaposi's sarcoma and human papillomavirus (HPV)-related malignancies such as cervical cancer and lip/oropharyngeal cancer, ${ }^{19}$ were not significantly different when patients with SLE and non-SLE patients were each compared with the general population. We do note that both the SLE and non-SLE groups had similarly increased risk of liver cancer compared with the general population, despite small differences in HCV positivity between the two groups (less frequently in SLE). ${ }^{20}$ The HIV-related malignancies such as Kaposi's sarcoma and HPV-related malignancies such as cervical cancer and lip/oropharyngeal cancer ${ }^{19}$ were not clearly different between patients with SLE and non-SLE patients. Likewise, both the SLE and non-SLE groups had similarly increased rates of Kaposi's despite HIV being more frequent in the non-SLE group.

The SLE group as a whole had a greater increase in risk of melanoma than non-SLE renal transplant recipients. When stratified by race or ethnicity, this increased risk was noticeable primarily in non-whites and Hispanics from the non-SLE transplant group. Since in the general population non-whites are less likely than whites to develop melanoma, we suspect that some risk factor in the renal transplant population is driving melanoma risk in this subset. ${ }^{21}$ Furthermore, additional analysis showed similar overall cancer by sex (data not shown), suggesting that sex was not a significant confounder or effect modifier. CMV positivity at time of 
Table 3 Standardised incidence ratios (SIRs) and 95\% Cls) in US systemic lupus erythematosus renal transplant recipients compared to the US general population stratified by race/ethnicity

\begin{tabular}{|c|c|c|c|c|c|c|c|}
\hline Cancer type & Observed cases* & Expected cases* & $\begin{array}{l}\text { Overall SIR } \\
(95 \% \mathrm{CI})\end{array}$ & $\begin{array}{l}\text { White SIR } \\
(95 \% \mathrm{CI})\end{array}$ & $\begin{array}{l}\text { Non-white SIR } \\
(95 \% \mathrm{Cl})\end{array}$ & $\begin{array}{l}\text { Hispanic SIR } \\
(95 \% \mathrm{CI})\end{array}$ & $\begin{array}{l}\text { Non-Hispanic SIR } \\
(95 \% \mathrm{CI})\end{array}$ \\
\hline All cancers & 1622 & 466 & 3.7 (2.1 to 5.7$)$ & 4.5 (1.9 to 7.0$)$ & 3.6 (2.1 to 5.1$)$ & $3.6(1.7$ to 5.6$)$ & 4.0 (2.1 to 5.8$)$ \\
\hline Lip/oropharyngeal & 791 & 11 & 72. (57.3 to 92.0$)$ & 58.8 (28.9 to 89.1$)$ & 69.9 (42.3 to 97.3$)$ & 69.4 (16.6 to 122.1$)$ & 59.9 (31.5 to 88.4$)$ \\
\hline Kaposi & 38 & 1 & 38 (35.2 to 141.1$)$ & 11.8 (5.0 to 39.7$)$ & 42.3 (12.1 to 97.5$)$ & 0 & 134.3 (10.0 to 278.0$)$ \\
\hline Neuroendocrine $†$ & 163 & 5 & 32.6 (30.7 to 50.2$)$ & 23.5 (6.9 to 40.1$)$ & 36.8 (9.2 to 64.4$)$ & 24.8 (21.0 to 39.5 ) & 23.0 (11.3 to 58.2$)$ \\
\hline Thyroid & 283 & 10 & 28.3 (16.2 to 41.2 ) & 25.5 (7.5 to 43.4$)$ & 51.0 (31.8 to 70.0$)$ & 31.7 (6.4 to 57.0$)$ & 26.5 (14.6 to 38.5$)$ \\
\hline Renal & 217 & 14 & 15.5 (12.3 to 21.7$)$ & 14.7 (9.7 to 19.6$)$ & 18.7 (8.6 to 28.7$)$ & $7.4(1.0$ to 14.3$)$ & 16.3 (9.8 to 22.8$)$ \\
\hline Cervical & 133 & 8 & 16.65 (3.0 to 27.3 ) & 14.3 (7.2 to 21.1$)$ & 19.0 (9.7 to 28.2) & $4.6(-) \ddagger$ & 23.3 (0.7 to 45.7$)$ \\
\hline Lymphoma & 293 & 22 & 13.3 (9.0 to 14.6$)$ & 12.3 (8.0 to 16.5$)$ & 16.8 (8.9 to 24.7$)$ & 19.1 (4.9 to 33.3 ) & $13.8(6.6$ to 21.1$)$ \\
\hline Liver & 40 & 6 & 6.64 (5.5 to 7.3$)$ & NA & NA & NA & NA \\
\hline Colorectal & 222 & 49 & 4.5 (3.2 to 6.1$)$ & $4.8(2.5$ to 7.1$)$ & $3.3(1.1$ to 5.6$)$ & $6.4(1.6$ to 14.5$)$ & 5.1 (3.1 to 7.1 ) \\
\hline Ovarian & 32 & 13 & $2.4(1.3$ to 5.6$)$ & $1.4(1.4$ to 1.5$)$ & 2.3 (2.2 to 2.4$)$ & 0 & $0.8 \mp(-)$ \\
\hline Melanoma & 27 & 20 & 1.4 (1.6 to 2.8$)$ & 1.8 (0.0 to 3.5$)$ & $19.9(0.0$ to 35.3$)$ & 0 & $1.6(0.7$ to 2.5$)$ \\
\hline Breast & 255 & 127 & $2.0(1.1$ to 3.1$)$ & 1.7 (0.8 to 2.6$)$ & 3.1 (1.8 to 4.4$)$ & $5.0(1.2$ to 8.8$)$ & 2.1 (1.2 to 3.1$)$ \\
\hline Lung & 43 & 65 & $0.7(0.6$ to 1.0$)$ & $0.8(0.3$ to 1.3$)$ & $0.4(0.2$ to 0.7$)$ & 0 & $0.9(0.6$ to 1.1$)$ \\
\hline Prostate & 54 & 163 & $0.33(0.01$ to 1.0$)$ & 0.1 (0.1 to 0.3$)$ & $0.5(0.0$ to 1.0$)$ & $0.9(0.5$ to 3.1$)$ & 0.4 (0.1 to 0.6$)$ \\
\hline
\end{tabular}

*Observed and expected cases reported per 100000 person-years.

†Neuroendocrine tumours included carcinoid, islet cell, medullary thyroid and pheochromocytoma.

\pm Only one case=not available due to small number of cases.

$\mathrm{NA}$, not available due to small number of cases.

Table 4 Standardised incidence ratios (SIRs) and 95\% Cls in US non-systemic lupus erythematosus renal transplant recipients compared with the US general population stratified by race/ethnicity

\begin{tabular}{|c|c|c|c|c|c|c|c|}
\hline Cancer type & Observed cases* & Expected cases* & $\begin{array}{l}\text { Overall SIR } \\
(95 \% \mathrm{Cl})\end{array}$ & $\begin{array}{l}\text { White SIR } \\
(95 \% \mathrm{CI})\end{array}$ & $\begin{array}{l}\text { Non-white SIR } \\
(95 \% \mathrm{Cl})\end{array}$ & $\begin{array}{l}\text { Hispanic SIR } \\
(95 \% \mathrm{CI})\end{array}$ & $\begin{array}{l}\text { Non-Hispanic SIR } \\
(95 \% \mathrm{CI})\end{array}$ \\
\hline All cancers & 1739 & 469 & $3.7(2.4$ to 5.7$)$ & $4.0(2.3$ to 5.7$)$ & 3.7 (2.3 to 5.2$)$ & 4.8 (3.2 to 6.4$)$ & $3.9(2.3$ to 5.5$)$ \\
\hline Lip/oropharyngeal & 665 & 11 & 60.4 (36.2 to 80.1$)$ & 47.9 (26.5 to 69.2$)$ & 59.5 (30.5 to 88.6$)$ & 91.1 (42.8 to 139.4$)$ & 48.0 (25.8 to 70.1$)$ \\
\hline Kaposi & 42 & 1 & 42 (55.2 to 89.9$)$ & 67.2 (54.8 to 79.5$)$ & 49.4 (24.6 to 64.2$)$ & $62.0(26.1$ to 97.9$)$ & 91.0 (71.4 to 110.5$)$ \\
\hline Neuroendocrine $†$ & 74 & 5 & 14.8 (11.3 to 58.2$)$ & 11.8 (2.6 to 21.1$)$ & 12.9 (2.4 to 23.5$)$ & 12.0 (1.6 to 22.4$)$ & 15.0 (2.4 to 25.5$)$ \\
\hline Thyroid & 238 & 10 & 23.8 (14.6 to 38.5$)$ & 21.3 (16.9 to 25.7$)$ & 42.4 (36.9 to 48.0$)$ & 30.4 (23.6 to 37.3$)$ & 21.8 (16.8 to 26.7 ) \\
\hline Renal & 142 & 14 & 10.1 (7.6 to 12.6$)$ & 7.7 (5.7 to 9.7 ) & 13.5 (10.1 to 16.9$)$ & 9.5 (6.7 to 12.3$)$ & 9.9 (7.4 to 12.4$)$ \\
\hline Cervical & 144 & 9 & 16.7 (11.7 to 21.6$)$ & 16.1 (11.1 to 21.0$)$ & $13.2(10.4$ to 16.0$)$ & $11.8(7.5$ to 16.1$)$ & 19.8 (13.5 to 21.0$)$ \\
\hline Lymphoma & 194 & 22 & 9.0 (7.4 to 10.5$)$ & $8.2(6.7$ to 98$)$ & 12.5 (10.1 to 15.0$)$ & $12.8(9.2$ to 16.4$)$ & 8.1 (6.6 to 9.6$)$ \\
\hline Liver & 17 & 7 & 9.0 (7.4 to 10.5$)$ & 2.5 (1.6 to 3.5$)$ & $2.6(1.5$ to 3.7$)$ & $2.6(2.0$ to 3.3$)$ & $3.1(2.0$ to 4.3$)$ \\
\hline Colorectal & 150 & 50 & 2.8 (2.2 to 3.4$)$ & 3.2 (2.2 to 4.3$)$ & 2.5 (1.6 to 3.5$)$ & 3.7 (2.5 to 4.9 ) & 2.8 (2.2 to 3.4$)$ \\
\hline Ovarian & 17 & 13 & $1.3(0.7$ to 1.8$)$ & $1.0(0.5$ to 1.5$)$ & $1.4(0.9$ to 1.9$)$ & $4.2(2.0$ to 6.3$)$ & $1.0(0.6$ to 1.4$)$ \\
\hline Melanoma & 22 & 20 & $1.0(0.7$ to 1.3$)$ & $1.0(0.7$ to 1.3$)$ & $15.2(6.9$ to 23.5$)$ & $5.0(1.1$ to 8.9$)$ & $0.9(0.6$ to 1.1$)$ \\
\hline Breast & 280 & 127 & 2.1 (1.3 to 2.8$)$ & $1.6(0.9$ to 2.3$)$ & $2.4(1.3$ to 3.5$)$ & $2.6(1.4$ to 3.9$)$ & $1.7(0.9$ to 2.6$)$ \\
\hline Lung & 90 & 64 & $1.4(1.0$ to 1.7$)$ & $1.4(0.9$ to 1.8$)$ & $1.2(0.8$ to 1.5$)$ & $1.3(1.1$ to 1.6$)$ & $1.4(1.0$ to 1.8$)$ \\
\hline Prostate & 65 & 163 & $0.4(0.2$ to 0.5$)$ & $0.3(0.2$ to 0.4$)$ & $0.3(0.2$ to 0.4$)$ & $0.4(0.1$ to 0.7$)$ & $1.1(0.2$ to 2.0$)$ \\
\hline
\end{tabular}

${ }^{*}$ Observed and expected cases reported per 100000 person-years.

†Neuroendocrine tumours included carcinoid, islet cell, medullary thyroid, Merkel cell and pheochromocytoma. 
Table 5 Adjusted Cox regression analysis estimating independent risk factors for the development of cancer in systemic lupus erythematosus (SLE) and non-SLE renal transplant recipients

\begin{tabular}{llll}
\hline Characteristic & HR & 95\% Cl & p Value \\
\hline $\begin{array}{l}\text { Age at transplant } \\
\text { Race }\end{array}$ & 1.0 & 1.0 to 1.0 & 0.0001 \\
$\quad \begin{array}{l}\text { White } \\
\text { Ethnicity }\end{array} \quad 1.2$ & 1.1 to 1.3 & 0.0001 \\
$\quad$ Hispanic & 1.4 & 1.0 to 2.0 & 0.10 \\
$\quad$ Sex & & & \\
$\quad$ Male & 1.0 & 0.9 to 1.0 & 0.90 \\
Current smoker & 2.2 & 1.2 to 4.0 & 0.02 \\
SLE & 1.1 & 0.9 to 1.3 & 0.30 \\
HCV positivity & 1.0 & 0.8 to 1.1 & 0.50 \\
HIV positivity & 0.4 & 0.2 to 0.9 & 0.03 \\
EBV positivity & 0.9 & 0.9 to 1.0 & 0.0003 \\
CMV positivity & 1.3 & 1.2 to 1.3 & 0.0001 \\
Dialysis vintage (years) & 1.0 & 1.0 to 1.0 & 0.004 \\
\hline CMV, cytomegalovirus; dialysis vintage, time on dialysis; & EBV, \\
Epstein-Barr virus; HCV, hepatitis C virus. &
\end{tabular}

renal transplantation was higher in the SLE versus the non-SLE group, $55.3 \%$ vs $52.5 \%, \mathrm{p}=0.0001$. CMV positivity was associated with higher risk of cancer.

Due to the limitations of the USRDS database, we were unable to assess certain relevant variables. We were unable to adjust for differences in other donor/recipient characteristics except as documented in table 1 . We were only able, for example, to estimate current (not past) smoking, but we still noted a significant association of smoking with cancer overall. ${ }^{17}$ Non-transplanted patients with SLE have an increased incidence of some types of cancer; ${ }^{10}$ the use of the general population as the reference group may be a confounding factor. In this study, we compared cancer incidence rates with the general population because of the need of reliable estimates for the cancer rates in each age/gender groups (as used in the SIR calculations), which requires large data set, unavailable for lupus patients only.

At baseline, patients with SLE are in fact less likely than the general population to undergo breast, colorectal and cervical cancer screening than patients without SLE. ${ }^{22}$ Better cancer screening follow-up after transplantation may partially explain the increased incidence of breast cancer in this study, whereas other studies have demonstrated a decreased breast cancer risk in the general SLE population. ${ }^{23}$ It should be kept in mind that the follow-up of our current study was relatively short (since the average duration of follow-up is half of the average follow-up in most general SLE cohort studies).

Another limitation of this study is the absence of data on medications used prior to and after renal transplantation, including immunosuppressive regimen posttransplant. We were also unable to assess duration of lupus or temporal trends in its treatment. Azathioprine and cyclophosphamide, often used for the treatment of lupus nephritis, have been linked to haematological malignancy and hepatobiliary cancer in transplant populations, ${ }^{24-26}$ although these have not been clearly linked to cancer in the general SLE population. Cyclophosphamide is associated with bladder cancer, non-melanoma skin cancers and haematological malignancies. ${ }^{27}{ }^{28}$ Furthermore, calcineurin inhibitors used in renal transplant patients may interfere with the antiviral mechanisms of natural killer cells, ${ }^{29}$ leading to the proliferation of HPV, which causes cervical and oropharyngeal cancers. ${ }^{30} \mathrm{~A}$ newer class of immunosuppressives, the mammalian target of rapamycin inhibitors, is hypothesised to have tumour-suppressive effects. ${ }^{31} 32$

The cancer SIRs for SLE transplant recipients are higher than the SIRs estimated from the general SLE population. ${ }^{10}$ This is most likely because in the current study we used Medicare claims data to ascertain cancer, which may overestimate cancer risk compared with cancer registry linkage (which has standardly been used in studies of cancer risk in the general SLE population). As well, much of the cancer risk data in the literature comes from clinically confirmed patients with SLE, we did not have clinical confirmation of SLE in the current study. Other potential explanation for the higher SIR in our current study is that patients with SLE who undergo transplantation may truly be at higher risk for cancer than the general SLE population, possibly because of their specific profiles of disease activity and drug exposures.

We have shown that the SLE group had an increased risk of melanoma versus the non-SLE group. In the SLE group, non-whites had an increased risk of melanoma and thyroid and renal cancers compared with other races, and Hispanics had an increased risk of ovarian cancer compared with non-Hispanics. Additional research is needed to elucidate the mechanisms underlying the increased risk of malignancy after renal transplantation, in particular the effect of race and ethnicity on post-transplant cancers. Prospective trials will be needed to study the cost-effectiveness of cancer surveillance in both SLE and non-SLE transplant groups.

\section{Author affiliations}

${ }^{1}$ Division of Rheumatology, Department of Medicine, Feinberg School of Medicine, Northwestern University, Chicago, Illinois, USA

${ }^{2}$ Department of Medicine, SUNY Downstate Medical Center, Brooklyn, New York, USA

${ }^{3}$ Division of Rheumatology, Department of Medicine, University of Calgary, Calgary, Alberta, Canada

${ }^{4}$ Department of Epidemiology and Biostatistics, McGill University, Montreal, Quebec, Canada

${ }^{5}$ Division of Research, SUNY Downstate School of Medicine, Brooklyn, New York, USA

${ }^{6}$ Walter Reed National Military Medical Center \& Uniformed Services University, Bethesda, Maryland, USA

Contributors All authors have participated in the study design, analysis and writing of the paper.

Funding This study was supported by the National Cancer Institute (NCI) (R03-CA173822) 
Disclaimer The data reported have been supplied by the United States Renal Data System (USRDS). The interpretation and reporting of these data are the responsibility of the authors and do not reflect the position or policy of the Department of Veterans Affairs, Department of Health and Human Services, National Cancer Institute, Department of Defense, US government or other organisations with which authors are affiliated.

Competing interests None declared.

Ethics approval Northwestern University, IRB project number: STU00065141.

Provenance and peer review Not commissioned; externally peer reviewed.

Data sharing statement No additional data are available.

Open Access This is an Open Access article distributed in accordance with the Creative Commons Attribution Non Commercial (CC BY-NC 4.0) license, which permits others to distribute, remix, adapt, build upon this work noncommercially, and license their derivative works on different terms, provided the original work is properly cited and the use is non-commercial. See: http:// creativecommons.org/licenses/by-nc/4.0/

\section{REFERENCES}

1. Maroz N, Segal MS. Lupus nephritis and end-stage kidney disease. Am J Med Sci 2013;346:319-23.

2. Ponticelli $\mathrm{C}$, Moroni $\mathrm{G}$. Renal transplantation in lupus nephritis. Lupus 2005;14:95-8.

3. Moroni G, Tantardini F, Gallelli B, et al. The long-term prognosis of renal transplantation in patients with lupus nephritis. Am J Kidney Dis 2005; 45:903-11.

4. Mojcik CF, Klippel JH. End-stage renal disease and systemic lupus erythematosus. Am J Med 1996;101:100-7.

5. Broder A, Khattri S, Patel R, et al. Undertreatment of disease activity in systemic lupus erythematosus patients with endstage renal failure is associated with increased all-cause mortality. $J$ Rheumatol 2011;38:2382-9.

6. Stewart JH, Vajdic CM, van Leeuwen MT, et al. The pattern of excess cancer in dialysis and transplantation. Nephrol Dial Transplant 2009;24:3225-31.

7. Villeneuve PJ, Schaubel DE, Fenton SS, et al. Cancer incidence among Canadian kidney transplant recipients. Am J Transplant 2007;7:941-8.

8. van Leeuwen MT, Grulich AE, Webster AC, et al. Immunosuppression and other risk factors for early and late non-Hodgkin lymphoma after kidney transplantation. Blood 2009;114:630-7.

9. Vajdic CM, McDonald SP, McCredie MR, et al. Cancer incidence before and after kidney transplantation. JAMA 2006;296: 2823-31.

10. Bernatsky S, Ramsey-Goldman R, Labrecque J, et al. Cancer risk in systemic lupus: an updated international multi-centre cohort study. $J$ Autoimmunity 2013;42:130-5.

11. Ni J, Oiu L-J, Hu L-F, et al. Lung, liver, prostate, bladder malignancies risk in systemic lupus erythematosus: evidence from a meta-analysis. Lupus 2014;19:284-92.

12. Parikh-Patel AR, White $\mathrm{RH}$, Allen $\mathrm{M}$, et al. Cancer risk in a cohort of patients with systemic lupus erythematosus (SLE) in California. Cancer Causes Control 2008;19:887-994.
13. Gayed M, Bernatsky S, Ramsey-Goldman R, et al. Lupus and cancer. Lupus 2009;18:479-85.

14. Sultan SM, loannou Y, Isenberg DA. Is there an association of malignancy with systemic lupus erythematosus? An analysis of 276 patients under long-term review. Rheumatology 2000;39:1147-52.

15. United States Renal Data System. 2015 USRDS annual data report: Epidemiology of kidney disease in the United States. National Institutes of Health, National Institute of Diabetes and Digestive and Kidney Diseases, Bethesda, MD, 2015.

16. [No authors listed]. How good are the data? USRDS data validation special study. Am J Kidney Dis 1992;20(Suppl 2):68-83.

17. Hurst FP, Altieri M, Patel PP, et al. Effect of smoking on kidney transplant outcomes: analysis of the United States Renal Data System. Transplantation 2011;92:1101-7.

18. Green M, Michaels MG. Epstein-Barr virus infection and posttransplant lymphoproliferative disorder. Am J Transplant 2013;13 (Suppl 3):41-54; quiz.

19. Frisch M, Biggar RJ, Engels EA, et al. Group Al-CMRS. Association of cancer with AIDS-related immunosuppression in adults. JAMA 2001;285:1736-45.

20. Fattovich G, Stroffolini T, Zagni I, et al. Hepatocellular carcinoma in cirrhosis: incidence and risk factors. Gastroenterology 2004;127 (Suppl 1):S35-50

21. Vajdic CM, van Leeuwen MT, Webster AC, et al. Cutaneous melanoma is related to immune suppression in kidney transplant recipients. Cancer Epidemiol Biomarkers Prev 2009;18:2297-303.

22. Bernatsky SR, Cooper GS, Mill C, et al. Cancer screening in patients with systemic lupus erythematosus. $J$ Rheumatol 2006;33:45-9.

23. Tessier Cloutier B, Clarke AE, Ramsey-Goldman R, et al. Breast cancer in systemic lupus erythematosus. Oncology 2013;85:117-21.

24. Hahn BH, McMahon MA, Wilkinson A, et al. American College of Rheumatology guidelines for screening, treatment, and management of lupus nephritis. Arthritis Care Res (Hoboken) 2012;64:797-808.

25. Morton LM, Gibson TM, Clarke CA, et al. Risk of myeloid neoplasms after solid organ transplantation. Leukemia 2014;28:2317-23.

26. Koshiol J, Pawlish K, Goodman MT, et al. Risk of hepatobiliary cancer after solid organ transplant in the United States. Clin Gastroenterol Hepatol 2014;12:1541-9.e3.

27. Knight A, Askling J, Granath F, et al. Urinary bladder cancer in Wegener's granulomatosis: risks and relation to cyclophosphamide. Ann Rheum Dis 2004:63:1307-11.

28. Faurschou M, Sorensen IJ, Mellemkjaer L, et al. Malignancies in Wegener's granulomatosis: incidence and relation to cyclophosphamide therapy in a cohort of 293 patients. J Rheumatol 2008;35:100-5.

29. Morteau O, Blundell S, Chakera A, et al. Renal transplant immunosuppression impairs natural killer cell function in vitro and in vivo. PLoS ONE 2010;5:e13294

30. Amador-Molina A, Hernández-Valencia JF, Lamoyi E, et al. Role of innate immunity against human papillomavirus (HPV) infections and effect of adjuvants in promoting specific immune response. Viruses 2013:5:2624-42.

31. Kauffman HM, Cherikh WS, McBride MA, et al. Post-transplant de novo malignancies in renal transplant recipients: the past and present. Transpl Int 2006;19:607-20.

32. Campistol JM, Albanell J, Arns W, et al. Use of proliferation signal inhibitors in the management of post-transplant malignanciesclinical guidelines. Nephrol Dial Transplant 2008;22(Suppl 1):36-41. 